http://doi.org/10.46754/gtc.2021.11.040

\title{
AESTHETIC QUALITY OF ISLAND TOURISM IN MALAYSIA'S EAST COAST REGION: DOES DURATION OF STAY MATTER IN SATISFYING TOURISTS?
}

\author{
Mazni Saad ${ }^{1}$, Ainun Khadijah Lokman' ${ }^{2}$, Mohd Hanafi Azman Ong ${ }^{3}$ \& Nor'Ain Othman ${ }^{4}$ \\ 1,2Department of Tourism, Kulliyyah of Languages and Tourism, International Islamic University Malaysia, \\ Pagoh Hub Education, 84600 Muar, Johor \\ ${ }^{3}$ Department of Statistics and Decision Sciences, Faculty of Computer and Mathematical Sciences, \\ Universiti Teknologi MARA Cawangan Johor (Kampus Segamat) 85000 Segamat, Johor \\ ${ }^{4}$ Faculty of Hotel and Tourism Management, Universiti Teknologi MARA (UiTM), Kampus Puncak Alam, \\ Bandar Puncak Alam, 42300 Selangor \\ (maznisaad@iium.edu.my, ainkhadijah36@gmail.com, napieong@uitm.edu.my, aindzul@gmail.com)
}

\begin{abstract}
The East Coast islands of Malaysia are becoming increasingly popular as a world-class nature tourism destination. Not only are they naturally beautiful and accessible, they are also attractive and appear as a destination image. However, whether satisfaction based on the aesthetic quality of the island is sufficient in determining a tourist's duration of stay is being questioned. This study, therefore, sets out two objectives to investigate the relationship between Aesthetic qualities and Tourist Satisfaction which are to investigate which aesthetic quality has a significant influence on tourist satisfaction of Malaysia's East Coast islands and to determine whether the length of stay has a significant influence on tourist satisfaction of the East Coast islands of Malaysia. This study used both quantitative and cross-sectional methods to collect data. Then a Smart PLS-SEM analysis was used on the 150 responses; the 5000 replication of samples reveals that all aesthetic qualities contributed to tourist satisfaction. The ANOVA analysis, supported by the post hoc multiple comparison analysis among the groups, the Least Square Difference (i.e., LSD) Fisher's Test, and Games-Howell Test, yielded intriguing results for the significant difference between the duration of stay groups on these islands. All aesthetic qualities, especially scenery, showed significant differences during a short stay. The findings would raise public awareness of the importance of sustaining the aesthetic quality of island tourism while also benefiting many stakeholders. There is also a need for more promotional efforts to extend the tourists' duration of stay. However, generalisations of the results of this study are limited to responses given mainly from three main islands of Terengganu.
\end{abstract}

KEYWORDS: Aesthetic qualities, island tourism, length of stay, satisfaction, Malaysia

\section{PURPOSE AND BACKGROUND}

The islands of the coast of Pahang, Malaysia are becoming increasingly popular as world-class nature tourism destinations. The East Coast islands facing the South China Sea have become full-fledged nature tourism destinations. Natural beauty and accessibility, among other things, attract and appear as a destination image, making Malaysia one of the most popular tourist destinations.

However, tourist loyalty is being questioned because tourism activities may impact the nature of the islands, resulting in a decrease in the number of tourists. Therefore, the purpose of this research is to investigate the relationship between aesthetic qualities (cleanliness, scenery, art/architecture, and genuineness) and Tourist Satisfaction. 
The study has two research objectives:

(1) to determine whether aesthetic qualities affect tourist satisfaction in Malaysia's East Coast islands and

(2) investigate which aesthetic qualities have a significant impact on tourist satisfaction in Malaysia's East Coast islands in terms of length of stay.

\section{METHODOLOGY}

This study investigates how the cleanliness, scenery, architecture, and genuineness of islands affect tourist satisfaction. The quantitative analysis and survey methodology of this study followed recommendations laid out by Creswell (2014) and Saunders et al. (2009). The demographic profile, research variables, and open-ended query were all tailored to the respondents of this study.

In developing the questionnaire sample, question items from Breiby and Slatten (2018) and Phillips et al. (2013) were adapted. The question items were then pretested among three experts whose comments were then considered for the final revision of the items for the pilot test. Later, using purposive ease sampling, the Google Forms program, which is a common electronic tool for collecting data nowadays, snowballed the respondents.

However, one of this medium's drawbacks is that researchers must find a suitable platform to reach as many people as possible. Nevertheless, a total of 150 responses were received over a one-month period. In terms of data collection, researchers used an automated medium to ensure that respondents answered all of the questions in the standardised questionnaire.

To analyse a relatively small data size of 150 samples, the Equation Partial Modeling with Least Squares (i.e. PLS-SEM) estimation multivariate data technique was used (Hair et al., 2017; Ong \& Puteh, 2017).

The PLS-SEM can be considered the best statistical data analysis method since it allows the researchers to test the indicators used for measuring targeted constructs based on convergent validity and discriminant validity (Hair et al., 2012; Henseler \& Chin, 2010). The significance test in this PLS-SEM analysis was computed using the Bootstrapping method, which can be considered more robust than the conventional t-test method (Hair et al., 2012; Henseler \& Chin, 2010).

As suggested by Hair et al. (2017), 5000 replications of the sample were computed to get reliable results for the empirical t-statistics and Bias Corrected (i.e., BCa) cultural bootstrap. For the comparison analysis, a series of One-Way Analysis of Variance (i.e., ANOVA) were conducted to assess the significant differences among the duration of stay groups toward all the targeted variables in this study. As for strengthening the ANOVA results, the Welch robustness test of equality of means was also used to support the result of the Statistics produced by the ANOVA analysis.

Finally, a post-hoc multiple comparison analysis was done among the groups to support the significant difference among the duration of stay groups. Two types of tests were used for this purpose: The Least Square Difference (i.e. LSD) Fisher's Test and Games-Howell Test.

\section{FINDINGS}

This study collected 150 responses from tourists who had visited any of Malaysia's East Coast islands in the past three years. After the 5000 replications of samples, the analysis reveals that all aesthetic qualities (cleanliness, scenery, art/architecture, and genuineness) contributed to tourist satisfaction when visiting the East Coast region's islands. 
The ANOVA analysis, supported by the post hoc among the groups, Least Square Difference (i.e., LSD) Fisher's Test, and Games-Howell Test, yielded intriguing results for the significant difference between the duration of stay groups in the islands. The duration of stay, scenery, architecture, and satisfaction showed positive and significant results, which concluded the overall research.

\section{CONCLUSION}

Aesthetic qualities of cleanliness, scenery, art/architecture, and genuineness contributed to the tourists' satisfaction. Only the Scenery and Architecture showed positive and significant results determining the tourists' satisfaction by staying longer in the islands. Tourists appreciate both nature and history values in island tourism, and these values must be kept constant for the sustainability of island tourism in the East Coast region.

\section{CONTRIBUTION/PRACTICAL IMPLICATIONS}

Academics and practitioners need to create awareness among the local communities on the importance of sustainability and its benefits. Where the private sector is concerned, a strong partnership and collaboration between travel operators, budget hotels, tourist associations and the local government could lead to improved infrastructure, facilities, amenities and activities for tourists and visitors, thus contributing to a more enjoyable and memorable holiday experience on the island.

This would mean longer stays, repeat visits, loyalty, and word-of-mouth information of the island to friends and relatives. During the pandemic crisis, various tourism sectors need to meet and review the current situation to re-strategise further development and sustainability of the beautiful scenic islands of the East Coast of Malaysia.

\section{REFERENCES}

Asan, K., Kaptangil, K., \& Kinay, A. G. (2020). Mediating role of perceived festival value in the relationship between experiences and satisfaction. International Journal of Event and Festival Management, 11(2), 255-271.

Lu, C, Weng, H., Chen, S. Chiu, C. W., M, H. Y., Mak, K. W., \& Yeung, T. C. (2020). How port aesthetics affect destination image, tourist satisfaction and tourist loyalty? Maritime Business Review, 5(2), 211 228.

Lupu, C., Rodrigues, A. I., Stoleriu, O. M., \& Gallarza, M. G. (2021). A textual and visual analysis of the intrinsic value dimensions of Romania: Towards a sustainable destination brand. Sustainability, 13(67), $1-23$. 